DESIGN E INOVAÇÃO SOCIAL

Metadesign 


\section{SOBRE O AUTOR}

\section{Caio Adorno Vassão | caio@caiovassao.com.br}

Lattes: http://lattes.cnpq.br/5857678399360729

É graduado, mestre e doutor pela FAUUSP, pesquisa a relação entre tecnologia e ambiente urbano há mais de 20 anos e desenvolveu uma visão abrangente para o metadesign. É consultor associado ao núcleo Naweb (FAUUSP). 


\section{INTRODUÇÃO}

Atualmente, o termo ecossistema supera visivelmente seu campo de aplicação exclusivo a estudos de ecologia, sustentabilidade e preservação ambiental, e, de modo mais geral, biologia. Ele encontra aplicação em setores como: ciências humanas, estudos em comunicação, tecnologia digital, urbanismo, comércio, dentre outros (NARDI; O'DAY, 1999; POSTMAN, 2007; BRISCOE; DE WILDE, 2006). Essa apropriação denota um alcance para o próprio conceito que exige sua elaboração competente para que não se perca o seu rigor.

A partir de um campo alargado de referências na filosofia, cibernética e fenomenologia da percepção, temos a oportunidade de generalização do conceito de ecologia, por meio da conjunção de diversos entendimentos, como: (i) ecologia entendida como a composição da complexidade da mente humana e do ambiente natural/social (BATESON); (ii) ecologia entendida como o processo perceptual e organização emergente da percepção (GIBSON, 1979), estando na percepção humana do mundo a pedra fundamental do processo científico (MERLEAU-PONTY, 1996); e (iii) ecologia entendida como uma articulação entre três níveis ecológicos (sociedade, psique e meio ambiente), fundamental para a sustentabilidade ambiental (GUATTARI, 1990). Temos ainda o reconhecimento, na filosofia da ecologia - ou "ecosofia" (NAESS, 1973) -, de que o desafio da sustentabilidade depende da compreensão de que a ecologia natural se sobrepõe à ecologia da sociedade e dos sistemas artificiais humanos em um único ambiente complexo e multifacetado.

A partir dessa noção alargada da ecologia, procuramos articular um campo epistemológico para a elaboração do conceito de ecossistema, que pode ser entendido tanto como (a) trivial, como (b) inusitado: em (a), o ecossistema é um objeto de conhecimento que descreve o modo como os seres vivos se articulam, conduzindo e sendo conduzidos por fluxos de matéria e energia; em (b), o ecossistema é o campo de sobreposição entre o natural e o artificial, permitindo reconhecer dinâmicas ecológicas em meio à cultura, ao comércio, à técnica, e à urbanidade, assim como promovendo uma nova articulação entre as noções de "concreto" e "abstrato", articulando-as como faces de uma mesma entidade. 
O entendimento do ecossistema como algo que inclui a sociedade humana e suas criações tecnológicas, as cidades e a política local/global exige a articulação de altas escalas de complexidade e de um arcabouço epistemológico incrementado que resulta em um novo ferramental de elaboração e comunicação das questões ecológicas. Acreditamos que esse ferramental deve ser de caráter genérico, para que seja acessível não apenas ao especialista (em ecologia, biologia e áreas afins), mas também aos profissionais de outras áreas (o arquiteto urbanista, o geógrafo, o engenheiro, o sociólogo, o antropólogo, o gestor administrador, o físico, o operador cultural, o trabalhador social, o designer de serviços etc.). Trata-se de operar um campo comum e acessível de entendimento, que possa incluir a população geral em debates e propostas que tratem da ecologia e dos ecossistemas.

A seguir, argumentamos que o metadesign pode ser uma abordagem adequada para a empreitada de tomar esse campo extenso de referências de modo pragmático e, portanto, aplicável à realidade cotidiana da organização dos processos humanos de modo sustentável, já que permite tanto o lido com entidades de extrema complexidade como o trabalho compartilhado em equipes de grande porte.

\section{METADESIGN, SUAS ORIGENS E MÚLTIPLAS APLICAÇÕES}

O metadesign é uma abordagem de projeto inicialmente proposta por Van Onck (1963), tendo como intenção ampliar a cientificidade do desenho industrial. Posteriormente, esse termo foi apropriado por filósofos, teóricos da arte e do design, biólogos e urbanistas: Virilio (1993) considera que o metadesign é o projeto do cotidiano, realizado pela própria sociedade; Giaccardi $(2003,2005)$ considera o metadesign o projeto que as comunidades criativas fazem de seu próprio processo criativo; Maturana (1998) o entende como o processo de autopoiésis, a autocriação desempenhada pelos seres vivos; George (1997) o entende como sinônimo de urbanismo, ou seja, a sociedade urbana criando a si mesma. Essa semântica variada encontra unicidade e rigor no entendimento da etimologia da palavra: o radical meta, do grego, é o movimento descontínuo, da transformação (metamorfose) e da flutuação dos níveis vitais (metabolismo); é a "meta" do objetivo e do caminho para o atingir 


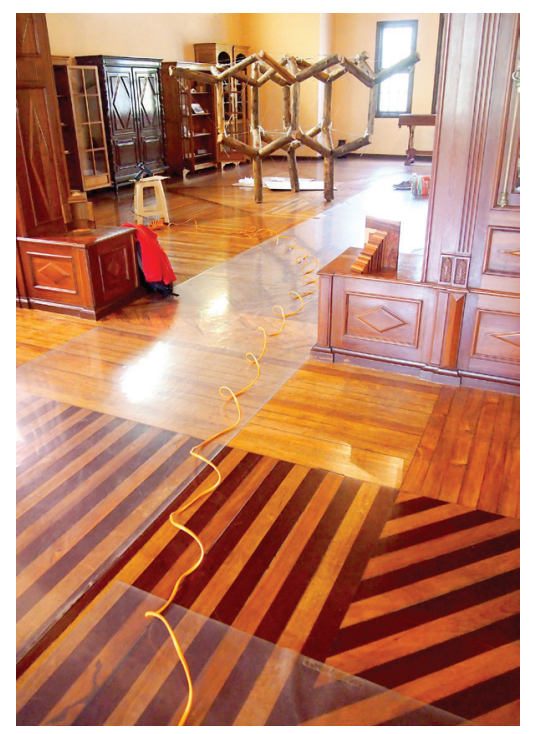

(meta-hodos: método); e a partir do termo "metafísica" (a Ontologia de Aristóteles) é o processo de autorreferência em campos variados do conhecimento, das artes e da tecnologia, como na metalinguagem e nos metadados. Na conjunção com o radical design, do inglês, entende-se o metadesign como o projeto de entidades que se alteram ao longo do tempo e o processo de cocriação de sistemas que se autoconstroem e/ou auto-organizam. Desse modo, pode-se compreender o metadesign como o projeto de entidades complexas das quais faz parte o autor do projeto. São exemplos as cidades (urbanismo), a economia (ciência econômica), as empresas (gestão empresarial) e também os ecossistemas de energia e matéria que incluem o ambiente urbano.

A partir dos conceitos de Caio Vassão (VASSÃO, 2006, 2008, 2010), é feita uma síntese de elementos oriundos da matemática, cibernética, biologia, ecologia, filosofia pós-estruturalista, artes, estética e poética, sociologia e antropologia, conformando uma abordagem transdisciplinar para o metadesign - a qual promove a desmistificação pragmática dos objetos de conhecimento ecologia e ecossistema e torna amplamente acessiveis: (a) sua descrição e (b) a descoberta de oportunidades de ação. Nesse sentido, o metadesign pode ser compreendido como uma abordagem para o projeto de ecossistemas, entendendo-os como entidades complexas por excelência, pré e pós-existentes a quem queira interferir neles, direcionálos ou desenvolvê-los. Ainda mais, o metadesign convida a compreender o objeto de conhecimento denominado ecossistema como uma entidade artificial, criada para mapear a concretude vivida tanto no meio ambiente como por meio da tecnologia - nas cidades, na economia e na cultura.

\section{METADESIGN COMO MEIO DE PROJETO E ANÁLISE DE ECOSSISTEMAS}

Argumentamos, a seguir, quanto à aplicação das "ferramentas cognitivas"

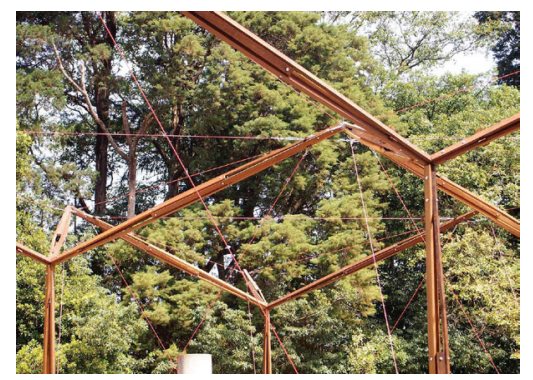
do metadesign, segundo Vassão, para a análise e projeto de ecossistemas.

\subsection{Primeiro argumento: topologia e diagramas}

A complexidade impõe que se elabore o ecossistema por meio da topologia. Desde o nascimento da ciência ecológica, a natureza foi descrita por meio de diagramas que expressam com clareza a sua extrema 
complexidade - as aplicações na biologia vão dos cladogramas evolutivos à descrição dos ecossistemas e nichos ecológicos. Do mesmo modo, Van Onck (1963) afirma que, para o metadesign, a topologia e os diagramas apresentam um meio de alta eficácia para a descrição do processo criativo e seus produtos. Outros, como Alexander (1994, 1966) e Baran (1964), utilizaram a topologia e diagramas para descrever cidades, arquitetura, relações sociais e redes de telecomunicação. Ainda, segundo Piaget, Fraisse e Vurpillot (1969) a topologia seria o modo basal de percepção do mundo e do espaço, das relações e composições, tanto na natureza, quanto no mundo tecnológico. Soma-se a isso a noção de que os níveis fundamentais de inteligência e pensamento humano são da ordem da topologia e dos "diagramas" - entendidos como a entidade fundamental da topologia. Por meio do "pensamento selvagem" (LEVI-STRAUSS, 1962), de sua ampliação para a dimensão político-social (CLASTRES, 1974) e da articulação desse entendimento antropológico com a natureza topológica da psique (DELIGNY, 2015; DELEUZE; GUATTARI, 1980), podem-se compreender os diagramas como formas que compõem o abstrato e o concreto de modo não binário. Nesse sentido, os diagramas não são meras "representações" da natureza e dos sistemas humanos, mas são "presentificações" de entidades: seu desenho tem o poder de operacionalizar as entidades diagramadas. Essa dimensão alargada dos diagramas e da topologia permite dinâmicas de projeto compartilhado (síncronos e assíncronos) que promovem uma forma de composição das forças sociais caracterizada pela polissemia (múltiplas interpretações), acessibilidade (de fácil e ampla compreensão) e horizontalidade hierárquica (igualdade sociopolítica).

\subsubsection{Topologia e tipologia - tipificação eficaz}

Apresentamos um esquema de tipificação dos ecossistemas desenvolvido por nós, a partir da expansão do esquema inicial proposto por Baran (1964). Trata-se de expandir a noção de bioma para incluir a sociedade e a tecnologia, superando, sem grande alarde, a distinção entre sistemas "naturais" e "artificiais", compreendendo-os, ambos, como sistemas "vivos".

A análise topológica permite reconhecer cinco tipos principais de sistemas centralizado, descentralizado, distribuído, saturado e anel - na natureza, na sociedade e na tecnologia, organizados em três grupos:
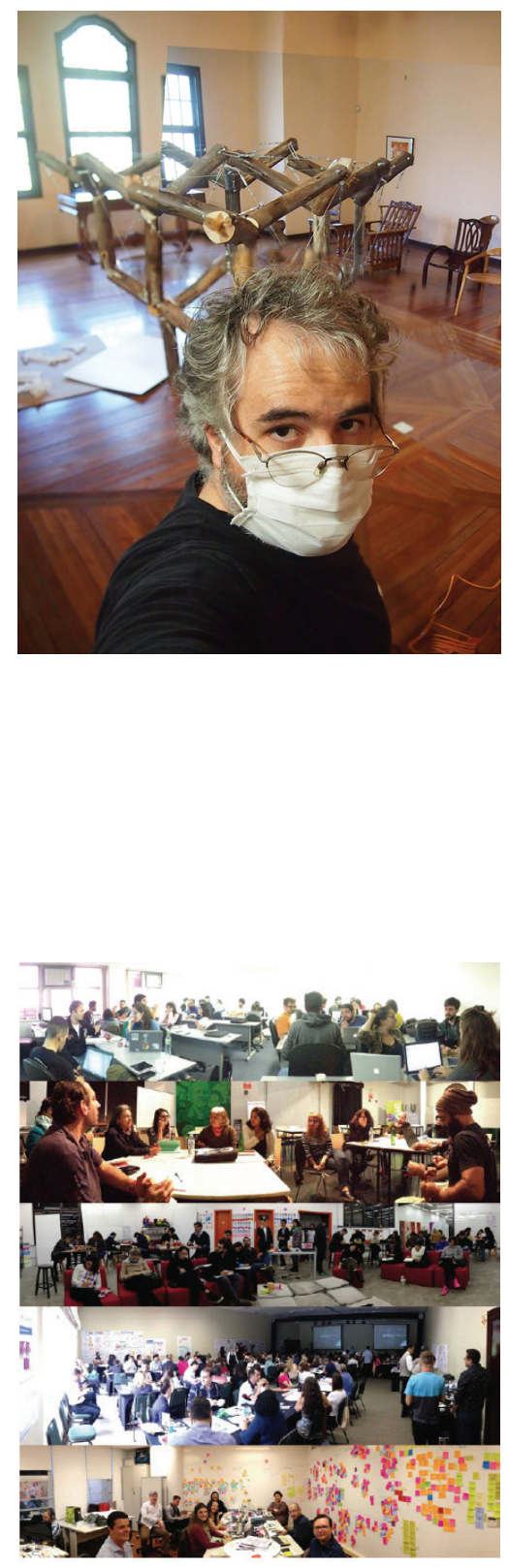

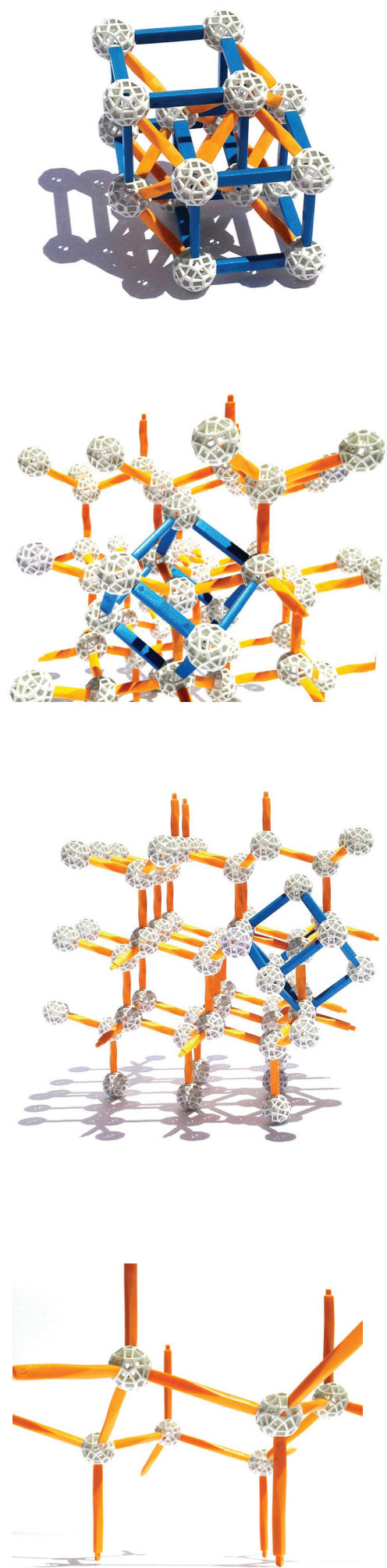

(i) Árvores, hierarquias, cladística e cladogramas (C: $B=0 ; D C: B<N)$.

(ii) Rizomas, organizações abertas, redes distribuídas e malhas (DT: B N; S: B > N).

(iii) Tubo digestivo, comunidade, direcionalidade, virtualidade ( $A N$ : $B=1$ ).
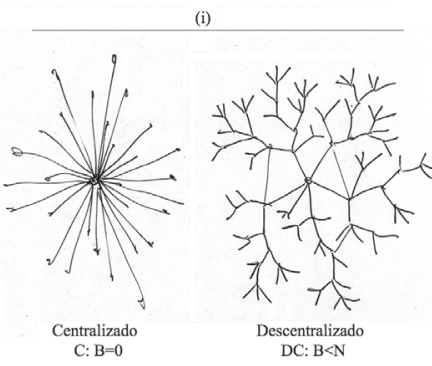

(ii)

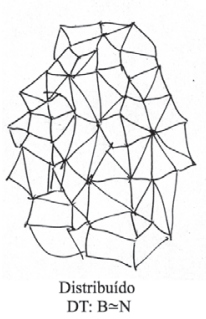

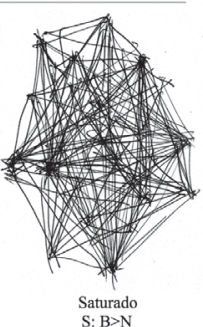

(iii)

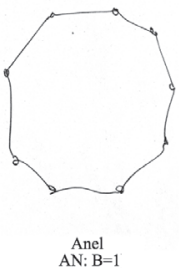

Os cinco tipos ou "padrões" topológicos em metadesign e ecossistemas. Os tipos estão, em geral, sobrepostos nos ecossistemas, e descrevem subsistemas ou subaspectos do ecossistema. Os três tipos descritos por Baran (1964) são: centralizados (centralidade absoluta), descentralizados (centralidade definida) e distribuidos (desprovidos de centralidade). A esses, adicionamos: saturado (todos com todos, sem centro) e anel (conexões binárias em torno de um centro virtual). A variável "N" é o número de "nós" que compõem o tipo topológico em especifico; a variável "B" é o número de "buracos" do tipo topológico - a relação entre as duas indica muito sobre o "tipo" topológico, especificamente, a natureza dos fluxos que podem operar em cada tipo.

Esses tipos de sistemas permitem compreender quais são as dinâmicas possiveis em cada tipo de ecossistema: (i) os sistemas cladísticos, dotados de ramificações, são hierárquicos e podem denotar tanto o processo de especiação na evolução como a cadeia de comando e controle em uma empresa, organização, governo ou instituição e também o sistema nervoso central, o sistema circulatório, por exemplo, nos seres vivos, assim como as bacias fluviais; (ii) os sistemas localmente conectados e hiperconectados (distribuídos e saturados) promovem a horizontalidade nas relações e a articulação local e telecomunicativa dos participantes do ecossistema - assim como denotam a organização dos tecidos vivos, pela vizinhança das células e pela transmissão de energia em um contínuo ambiental (atmosfera, oceano, por exemplo); e (iii) os sistemas anelares promovem a construção de níveis de abstração mais sofisticados, pois indicam tanto a direcionalidade de sistemas ciclônicos como a existência de entidades virtuais, ou seja, culturais - indicam, desse modo, a direcionalidade espaçotemporal dos seres vivos dotados de tubo digestório, obrigando-os 
a se mover à procura de alimento, motivados pelo impulso à satisfação do desejo. Essa análise envolve reconhecer a sobreposição desses padrões em subsistemas que compõem um "metassistema". Para dar um exemplo: a Internet é um sistema distribuído (DT) em seu modo fundamental de operação, mas é um sistema centralizado (C) em seu substrato de software (o chamado "Internet Protocol"); já a percepção do público da rede é de um sistema saturado (S), pois aparenta conectar todos os usuários, individualmente, entre si; mas o ordenamento territorial da Internet é um sistema descentralizado (DC), compondo-se de redes locais, metropolitanas, regionais, continentais e globais. Dependendo da leitura que se faz do ecossistema, percebese um aspecto diferente que se ordena de acordo com uma topologia específica, a qual permite operações e funções específicas.

\subsection{Segundo argumento: abstração, ontologias, monstros e quimeras}

Para descrever o mundo, assim como denominar ações eficientes sobre ele, utilizamos a linguagem. Ela "encapsula" entidades de extrema complexidade em denominações simples. É esse encapsulamento que preocupa muitos teóricos da complexidade, como Morin (2005), que denuncia o encapsulamento da complexidade em denominações reducionistas. Mas, sem a linguagem, não podemos compartilhar conhecimento de modo eficiente.

A linguagem expressa uma ontologia que contempla a existência de um numerosíssimo conjunto de entidades. Na maior parte das vezes, a linguagem e a ontologia se compõem a partir do senso comum. Mas, no campo científico, existe a pretensão de que tenhamos nos purgado de todo preconceito "antropomórfico". No entanto, devemos assumir o quanto a ciência é uma empreitada humana (LATOUR, 2000) que contém nossas crenças, mesmo que seja apenas a crença na própria sintaxe como diria Nietzsche.

O encaminhamento que o metadesign dá para essa questão é a de duvidar constantemente de nossos modelos, denominações, encapsulamentos, descrições e palavras. De modo pragmático, isso significa estar continuamente disponível para a criação de novas ontologias. Para tanto, uma atividade importante é a construção de vocabulários compartilhados
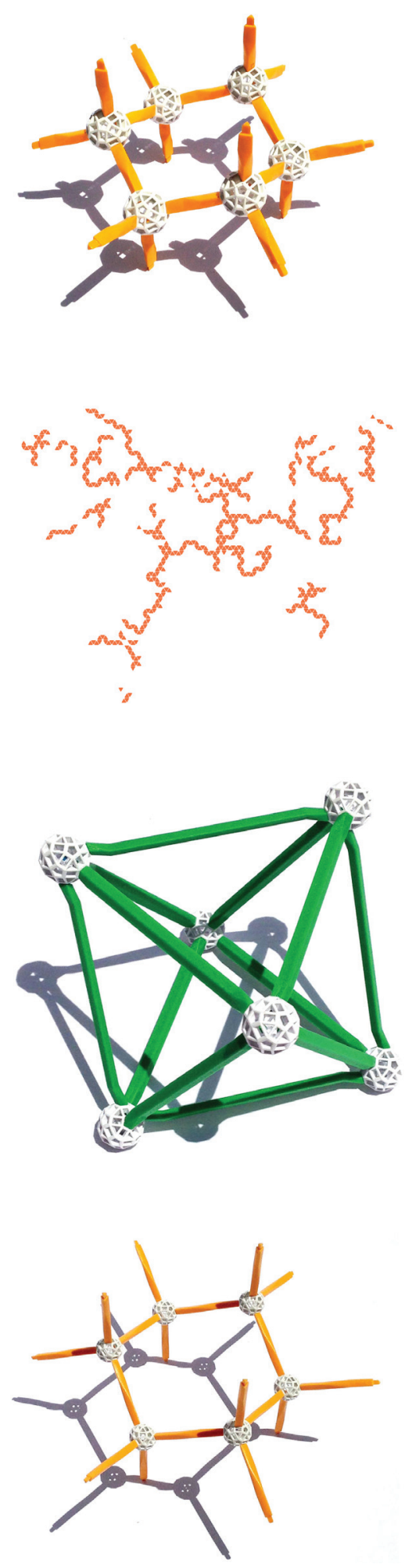
(A)

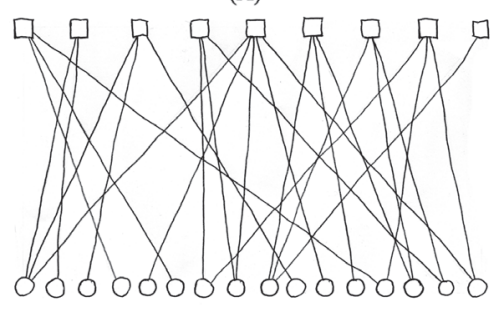

$\downarrow$

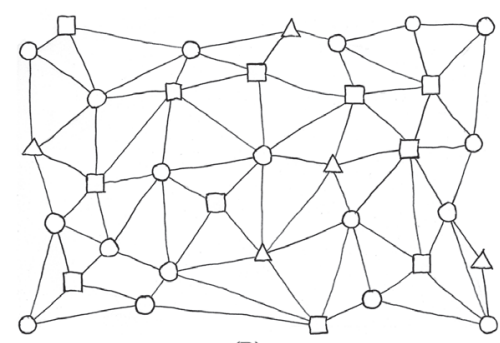

(B)

Figura 3: (A) outra forma de construir ontologias seria por meio da fuga da taxonomia, fazendo uma folksonomia, a "paraclassificação" das entidades a partir de "operadores" (口) que "etiquetam" ("tagging") as "entidades" 0 ), o que permite sua denominação de modo inclusivo, e não exclusivo (como na taxonomia), ou seja, promovendo a construção de significado pela associação entre "operadores" e "entidades" de modo não hierárquico. (B) Mas não demora muito para que quem esteja fazendo o "tagging" perceba que os "operadores" e "entidades" compartilham o mesmo nível ontológico, ou seja, em certa medida, todos os "operadores" são "entidades" e vice-versa. pelas comunidades propositoras por meio da criação coletiva de taxonomias e ontologias.

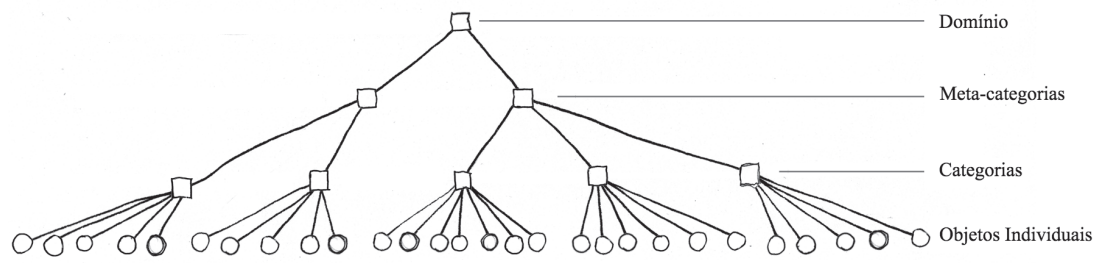

Uma árvore taxonômica esquematizada. Uma das práticas mais eficazes de se construir uma ontologia é pela composição de uma árvore taxonômica iniciando-se pelos "objetos individuais"; em seguida, agrupam-se tais objetos em "categorias" e depois em "metacategorias", em quantos niveis sejam necessários, até se chegar ao "domínio". Estamos também subindo, de baixo para cima (bottom-up), para níveis de abstração mais elevados, em que a escala de complexidade também se incrementa. Trata-se de uma dinâmica de compartilhamento de conhecimento e entendimento por meio da indução característica do método científico.

Por princípio, devemos distinguir entre o que é o "concreto" - o que existe independentemente das denominações que possamos fazer dele - e o "real" - o conjunto extenso e complexo de representações, modelos, denominações, encapsulamentos - e saber que mesmo as representações trafegam pelo mundo concreto, compartilhando existência com as próprias entidades que pretendem representar (KORZYBSKI, 1933). A partir disso, podemos aceitar que nenhum modelo pode dar conta da concretude que pretende representar, ao mesmo tempo que assumimos que a construção de representações é uma atividade resultante de criatividade coletiva. Desse modo, há sempre um hiato entre o que sabemos sobre o mundo e o que ele é de fato. Em especial, esse hiato se manifesta na diferença entre o que acreditamos que será o futuro de um ecossistema e o que ele revela ser de fato. Trata-se do fenômeno da "emergência", em que os sistemas dotados da capacidade de auto-organização revelam características "emergentes", ou seja, imprevistas.

\subsection{Terceiro argumento: intencionalidade, auto-organização e emergência}

Em mitologia, psicologia e biologia, um "monstro" é uma entidade para a qual não há lugar na ontologia estabelecida. A emergência de "monstros" 
e "quimeras" (monstros nos quais se podem reconhecer subentidades que pertencem a categorias ontológicas já conhecidas) é inevitável e deve ser vista como uma oportunidade de compreender melhor a concretude em que vivemos. Nesse sentido, o "monstro", ou o "desvio", pode ser visto, na natureza, como uma nova linhagem evolutiva, oriunda de mutações, ou, na cultura, como uma inovação, a composição de tecnologias conhecidas em uma nova entidade que passa a circular na sociedade. As coisas novas emergem de combinações que transcendem as taxonomias, ontologias e cosmologias em operação.

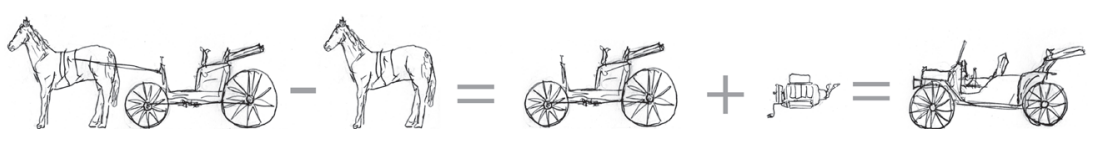

Monstros e quimeras. A composição de novas entidades em tecnologia opera, na maior parte das vezes, na combinação de entidades conhecidas com novas entidades, estas sim desconhecidas. A princípio, tais entidades são entendidas como quimeras. O automóvel é um bom exemplo: pelos primeiros trinta anos de sua história, ele foi conhecido pela denominação quimérica "carruagem sem cavalos".

Weaver (1948) afirmou que a ciência precisava reconhecer um terceiro tipo de sistema na natureza: além dos (i) sistemas simples (mecanísticos e determinísticos) e dos (ii) sistemas complexos desorganizados (probabilísticos e estatísticos), haveria os (iii) sistemas complexos organizados (autoorganizados, não determinísticos, emergentes). Nessa terceira categoria estariam todos os seres vivos, a economia, a sociedade, a cultura, a ecologia e os ecossistemas. Já que todas as intenções criativas da humanidade incorrem em consequências imprevisíveis em longo prazo, a abordagem mais adequada é o que podemos chamar de "acoplamento coevolutivo", que conecta as intenções propositivas às suas consequências, incorrendo em revisões periódicas: a emergência de "monstros" e "quimeras" deve ser acompanhada por ontologias dinâmicas, que norteiem a organização de nossas empreitadas e sistemas sociais. No entanto, tende-se a implementar inovações na macroescala da sociedade sem que sucessivas etapas de escalabilidade sejam trafegadas. Esse é o provável motivo pelo qual tantos desastres ecológicos tenham ocorrido ao longo do período industrial.

\subsubsection{Ação demiúrgica e ação ecossistêmica}

A rigor, a própria ideia da "criação do novo" é uma atividade sociocultural de composição: a noção do que venha a ser "criação" e

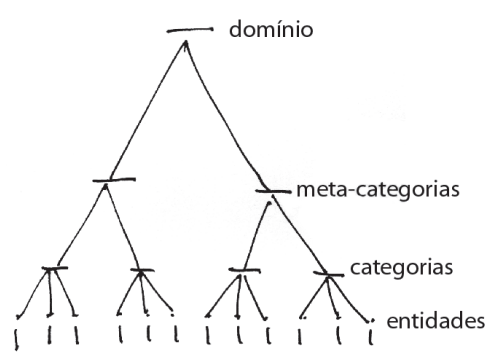

(A)

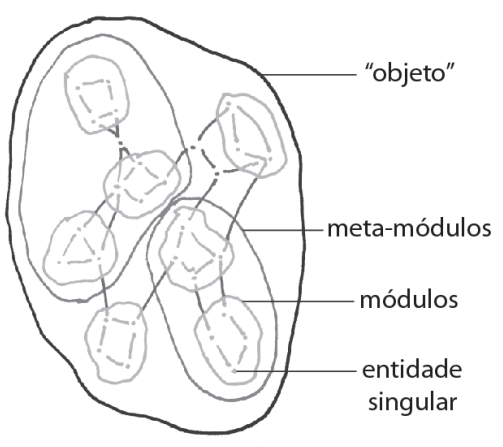

(B)

Figura 4: taxonomias e modelos são formas complementares para o entendimento abstrato de uma entidade.

(A) Taxonomias categorizam entidades por similaridade e as agrupam em conjuntos para classificação - o número de niveis de abstração (categorias agrupadas em metacategorias) varia de acordo com a complexidade do sistema em questão. (B) Modelos são composições que articulam entidades de modo hierárquico, agrupando entidades em módulos, em meta-módulos em quantos niveis de abstração forem necessários para se compor o modelo do objeto, o sistema, o processo ou o ecossistema. Quanto mais formal essa composição, mais bem definidos são os módulos - a dificuldade em se estabelecer os limites ou fronteiras de um módulo indica a informalidade ou a paraformalidade de um sistema. 


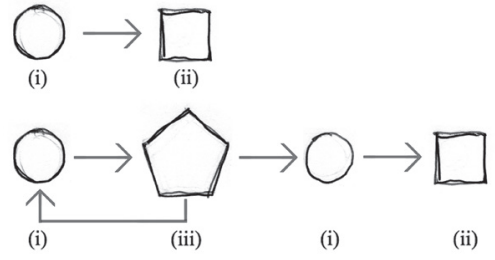

Projeto procedimental. Na mentalidade tradicional em projetos, o (i) projetista (ou "designer") tem uma relação direta com o (ii) objeto do projeto. Já em sistemas complexos (e ecossistemas), o (i) projetista só pode ter uma relação indireta com (ii) o objeto do projeto, mediada por um (iii) "procedimento", que pode ser de natureza legislativa, computacional, epistemológica etc. Esse (iii) procedimento informa outros designers ou o próprio designer inicial quanto ao que pode acontecer no contexto de proposta. (GEORGE, 1997) "criatividade" é compreendida como a composição de algo novo a partir do velho, do pré-existente. Essa combinação do que já existe com uma nova entidade pode ser chamada de noção greco-romana de criação, em contraste à noção judaico-cristã de criatividade, que compreende a criação como um ato "demiúrgico" que não parte de entidades préexistentes (MUNARI, 1998). E é importante frisar que é essa segunda noção de criatividade que norteia, ainda hoje, a maior parte das empreitadas humanas.

Haveria, então, dois modos de ação: um modo de agir "demiúrgico" e um modo de agir "ecossistêmico". O primeiro compreende que as ações humanas se justificam em si mesmas e que as ontologias existentes dão conta do mundo; ou seja, ignora as características emergentes da natureza e da cultura, rotulando-as como "ruído" ou "erro", ambos devendo ser "corrigidos". O segundo compreende que as ações humanas coevoluem imersas em um ecossistema que em muito supera nossas capacidades de compreendê-lo, e exige que reconstruamos periodicamente as ontologias para acomodar as monstruosidades a que nossas ações dão origem, assim como a ampliação constante do conhecimento que emerge de nossa interação com a natureza e em sociedade.

\subsection{Quarto argumento: escalas de ação, procedimentos e ação indireta}

A relação de quem cria uma coisa simples, como uma cadeira, por exemplo, é também simples e imediata, ou seja, as ações do designer têm repercussão direta sobre o objeto que cria. No entanto, a operação sobre um ecossistema urbano, por exemplo, envolve um grau de complexidade muito superior. Segundo George (1997), o urbanismo é uma operação de metadesign, e o metadesigner deve, antes, operar sobre os métodos que são os itens do planejamento urbano: plano diretor, zoneamento, legislação e índices de ocupação. A cidade, em si, emergiria da aplicação desses métodos. Quanto a outros tipos de ecossistema, os métodos podem ser muitíssimo variados, mas certamente incluem os já existentes em ciências ambientais, física, química e ciência em geral. 0 metadesign seria capaz de articular esses métodos em processos e procedimentos que deem conta da envergadura do ecossistema. 


\subsubsection{Objetos e procedimentos}

Operar por meio de procedimentos, ou seja, de modo indireto, envolve abandonar a crença de que é possível concentrar-se em "objetos" para se elucidarem ecossistemas. O próprio "objeto" ecossistema é, rigorosamente, uma abstração, uma construção eficaz de representação, como o mapa que se refere ao território (KORZYBSKI, 1933). No metadesign, os objetos são substituídos pelos próprios métodos e procedimentos, cuja construção torna-se o meio pelo qual a interferência sobre o ecossistema pode ser exercida.

Do ponto de vista pragmático, o "método" de maior alcance é a legislação: a construção de políticas públicas, regulamentação e normas e a definição de métodos considerados "boas práticas" é o meio mais comum para a interferência de grande alcance tempo-espacial não só em ecologia e sustentabilidade, mas também na construção de ecossistemas urbanos, comerciais e comunitários. Com efeito, a construção de meios para que se possa dialogar na macroescala da sociedade sobre as modalidades de legislação, sua caracterização específica, seus modos de aplicação, exigem que métodos de diálogo coletivo e colaborativo sejam construídas, desenvolvidas e operadas pelos metadesigners. No entanto, ponderar sobre a própria natureza desse diálogo, seu alcance e relação com os métodos das ciências e da própria epistemologia é uma empreitada que se avizinha para que a sustentabilidade ecológica seja, de fato, legítima do ponto de vista sociopolítico (NAESS, 1973; GUATTARI, 1990; BATESON, 1972).

\section{CONCLUSÃO: ONTOLOGIAS QUE ARTICULEM A DUALIDADE "NATURAL/ARTIFICIAL"}

O ecossistema é uma construção abstrato-concreta. Trata-se, a rigor, de um fato cultural e, portanto, trafega pelo mundo como os outros objetos culturais: como entidades criadas pela humanidade. Reconhecer a concretude do ecossistema é também reconhecer sua abstração, como objeto simbólico e representacional. É por isso que podemos falar de ecossistemas, no plural - já que se trata da elaboração de múltiplas entidades abstratas, os ecossistemas, que são as elaborações individuais a respeito de uma entidade geral, o ecossistema, entendido 
como um todo. No entanto, como qualquer outro ser vivo do planeta, a própria humanidade é parte do ecossistema natural. Nesse sentido, operacionalizar a governança em ecossistemas envolve o contínuo aprimoramento de ontologias que articulem as dualidades "concreto/ abstrato" e "natural/artificial". Essa é uma empreitada sociocultural e requer um ferramental adequado que possa promover o diálogo ampliado em múltiplos âmbitos da sociedade e que reconheça o dinamismo tanto dos ecossistemas como das ontologias que visam descrevê-los e ativá-los.

Consideramos que o ferramental do metadesign é uma adição importante, senão crucial, para o incremento da governança em projetos de sustentabilidade ambiental, permitindo a análise, descrição e ação em ecossistemas de modo acessivel a uma ampla gama sociocultural. Suas aplicações podem se dar em: análise da ecologia e sustentabilidade; análise ecossistêmica de modelos de negócio; compatibilização de sistemas artificiais e naturais; e incremento da legitimidade dos modelos de governança. $O$ estudo e aplicação consciente do metadesign convidam ao incremento do rigor de forma simplificada e, assim, incrementam a viabilidade das propostas em ecologia, ecossistêmica e sustentabilidade ambiental.

\title{
5 REFERÊNCIAS
}

\author{
ALEXANDER, Christopher W. Notes on the synthesis of form. Harvard University Press, 1994 \\ City is a mechanism for sustaining human contact. Institute Urban \& Regional \\ Development, Berkeley, 1966. \\ BARAN, Paul. On distributed communications: Introduction to distributed communications \\ networks. Santa Monica, California: Rand Corporation, 1964. Disponível em: <http://www.rand. \\ org/pubs/research_memoranda/RM3103/>. Acesso em: 17 abr. 2017. \\ BATESON, Gregory. Steps to an ecology of mind. 2. ed. Chicago: University of Chicago Press, 2000. \\ BRISCOE, Gerard; DE WILDE, Philippe. Digital ecosystems: evolving service-oriented \\ architectures. In: IEEE First International Conference on Bio Inspired Models of Network, \\ Information and Computing Systems, BIONETICS, 2006 \\ CLASTRES, Pierre. A sociedade contra o Estado: pesquisas de antropologia política. São Paulo: \\ Cosac \& Naify, 2003 \\ DELEUZE, Gilles; GUATTARI, Félix. Mil platôs: capitalismo e esquizofrenia. Rio de Janeiro: Editora \\ 34, 1995. \\ DELIGNY, Fernand. O aracniano e outros textos. São Paulo: n-1 edições, 2015.
}


GEORGE, R. Varkki. A procedural explanation for contemporary urban design. In: CARMONA, Matthew; TIESDELL, Steven. Urban Design Reader. 2006. Originalmente publicado em: Journal of Urban Design, 2 (2), p. 143-161, 1997.

GIACCARDI, Elisa. Principles of Metadesign: processes and levels of co-creation in the new design space. Tese (Doutorado) - Universidade de Plymouth, 2003.

_..._._. Metadesign as an Emergent Design Culture. Leonardo, 38:2, August, 2005.

GIBSON, James Jerome. The Ecological Approach to Visual Perception. Boston: Houghton Mifflin, 1979.

GOULD, Stephen Jay; ELDREDGE, Niles. Punctuated equilibria: the tempo and mode of evolution reconsidered. Paleobiology, 3 (2), p. 115-151, 1977.

GUATTARI, Félix. As três ecologias. Campinas: Papirus, 1990.

JACOBS, Jane. Morte e vida de grandes cidades. São Paulo: Martins Fontes, 2007.

KORZYBSKI, Alfred. Science and sanity: an introduction to non-aristotelian systems and general semantics. Institute of General Semantics, 1994. Disponivel em: <http://esgs.free.fr/uk/art/ sands.htm>. Acesso em: 17 abr. 2017.

LATOUR, Bruno. Ciência em ação: como seguir cientistas e engenheiros sociedade afora. São Paulo: Editora Unesp, 2000.

\section{LÉVI-STRAUSS, Claude. O pensamento selvagem. Campinas: Papirus, 1989.}

MATURANA, Humberto. Metadesign: Human beings versus machines, or machines as instruments of human designs?", 1998. Disponivel em: <http:/www.inteco.cl/articulos/ metadesign.htm>. Acesso em: 17 abr. 2017.

MAYR, Ernst. Cladistic analysis or cladistic classification? Journal of Zoological Systematics and Evolutionary Research, 12, p. 94-128, 1974.

MCLUHAN, Herbert Marshall. A Galáxia de Gutemberg: a formação do homem tipográfico. São Paulo: Editora Nacional, 1972

MERLEAU-PONTY, Maurice. Fenomenologia da percepção. São Paulo: Martins Fontes, 1996.

MORIN, Edgar. Introdução ao pensamento complexo. Porto Alegre: Sulina, 2005.

MUNARI, Bruno. Das coisas nascem coisas. São Paulo: Martins Fontes, 1998.

NAESS, Arne. The Shallow and the Deep, Long-Range Ecology Movement. Inquiry, 16, p. 95-100, 1973. Disponível em: <http://www.alamut.com/subj/ideologies/pessimism/Naess_ deepEcology.html>. Acesso em: 17 abr. 2017.

NARDI, Bonnie A.; O'Day, Vicki L. Information ecologies: using technology with heart. Cambridge, Massachussetts: MIT Press, 1999.

O'HARA, Robert J. Mapping the space of time: temporal representation in the historical sciences. In: GHISELIN, M. T.; Pinna, G. (Ed.). New Perspectives on the History of Life: Systematic Biology as Historical Narrative. Memoirs of the California Academy of Sciences, 20, p. 7-17, 1996.

PIAGET, Jean; FRAISSE, Paul; VURPILLOT, Éliane. Tratado de psicologia experimental. Volume VI, A percepção. Rio de Janeiro: Forense, 1969.

POSTMAN, Neil. What is media ecology. In: What is media ecology definitions. 2007. Disponivel em: <http://www.mediaecology.org/media_ecology/>. Acesso em: 17 abr. 2017. 
TENNER, Edward. Why things bite back: technology and the revenge of unintended consequences. New York: Vintage Books, 1997.

VAN ONCK, Andries. Metadesign. Tradução de Lúcio Grinover. Bibliografia FAUUSP, 1965.

VASSÃO, Caio Adorno. Metadesign: ferramentas, estratégias e ética para a complexidade. São Paulo: Blucher, 2010.

Arquitetura livre: complexidade, metadesign e ciência nômade. Tese (Doutorado) Faculdade de Arquitetura e Urbanismo, Universidade de São Paulo, 2008.

Design de interação: uma ecologia de interfaces. In: Anais do $7^{\circ}$ Congresso de Pesquisa e Desenvolvimento em Design - $7^{\circ}$ P\&D. Curitiba: CEUNSP, 2006.

VIRILIO, Paul. A arte do motor. São Paulo: Estação Liberdade, 1996.

WEAVER, Warren. Science and complexity. American scientist, Rockefeller Foundation, New York City, 36, p. 536, 1948. 